\title{
EFEITOS DO CLONAZEPAM NA ESQUIVA INIBITÓRIA NO PEIXE-DOURADO (CARASSIUS AURATUS)
}

\author{
EFFECTS OF CLONAZEPAM IN INHIBITORY AVOIDANCE IN GOLDFISH \\ (CARASSIUS AURATUS)
}

\author{
Paula Danielle Palheta Carvalho ${ }^{1}$ e Amauri Gouveia Jr. \\ UNIVERSIDADE FEDERAL DO PARÁ
}

\begin{abstract}
RESUMO
O objetivo do presente trabalho foi verificar o efeito do clonazepam na esquiva inibitória (EI) de um ambiente branco em peixes-dourados, descrito como aversivo para peixes dessa espécie. Foram utilizados 30 peixes dourados distribuídos em quatro grupos, conforme a concentração de fármaco $(0 \mathrm{mg} / \mathrm{ml}, \mathrm{n}=9 ; 0,001 \mathrm{mg} / \mathrm{ml}, \mathrm{n}=7 ; 0,003 \mathrm{mg} / \mathrm{ml}, \mathrm{n}=7 ;$ e $0,006 \mathrm{mg} / \mathrm{ml}, \mathrm{n}=7)$. A droga foi administrada por via hídrica em $86 \mathrm{ml}$ de água por 180 segundos. Para EI, foi utilizado um aquário dividido em dois compartimentos, um preto e um branco, por uma porta corrediça, sendo o animal inicialmente colocado no compartimento preto. Após $180 \mathrm{~s}$, a porta foi removida e o tempo de travessia para o compartimento branco foi registrado (latência), cada travessia correspondendo a uma tentativa, sendo sete no total. Os dados foram analisados por ANOVA de duas vias seguida do teste de Dunnet. Os resultados indicaram diferença estatisticamente significativa na latência entre as tentativas, com aumento da latência. $\mathrm{O}$ teste de Dunnet mostrou diferença significativa entre as tentativas 1 e 6 e 1 e 7 e entre os grupos controle e grupo com a concentração de $0,006 \mathrm{mg} / \mathrm{ml}$. Os dados indicam: 1) redução do valor aversivo do lado branco, o que demonstra o efeito ansiolítico do clonazepam; e 2) que o clonazepam não impediu a esquiva inibitória.
\end{abstract}

Palavras-chave: esquiva inibitória, clonazepam, Carassius auratus.

\begin{abstract}
The aim of this study was to verify the effect of the clonazepam in inhibitory avoidance (IA) of the white environment in goldfish. Thirty goldfish were divided in 4 groups according to drug-concentração: $0 \mathrm{mg} / \mathrm{ml}-(\mathrm{N}=9) ; 0,001 \mathrm{mg} / \mathrm{ml}-(\mathrm{N}=7)$; $0,003 \mathrm{mg} / \mathrm{ml}-(\mathrm{N}=7)$ and $0,006 \mathrm{mg} / \mathrm{ml}-(\mathrm{N}=7)$. The drug was diluted in $86 \mathrm{ml}$ of water along $180 \mathrm{~s}$. For IA, was used an aquarium divided in two chambers, one black and other white, with the animal initially placed in the black chamber. After $180 \mathrm{~s}$, the door was opened and the time spent to cross to the white compartment was recorded (latency). The data were analyzed for ANOVA of two-way followed by Dunnet test. The results indicated statistically significant differences in latency between trials with increase of latency. The Dunnet test indicated significant differences between the trials 1 and 6 and 1 and 7 and between control group and the group that received the concentration of $0,006 \mathrm{mg} / \mathrm{ml}$. The data indicate: 1) reduction of aversive property of white environment, what demonstrated the anxiolytic effect of clonazepam; and 2) clonazepam did not prevent the inhibitory avoidance.
\end{abstract}

Keywords: inhibitory avoidance, clonazepam, Carassius auratus.

A ansiedade é uma das emoções relacionadas com a presença de uma ameaça real ou potencial, seja porque o ambiente é novo, seja porque nele esteve presente um estímulo potencialmente aversivo, gerando, assim, um conflito de aproximação e evitação desse ambiente (Blanchard \& Blanchard, 1988; Gray \& McNaughton, 2000 como citado em Graeff, 2007) pela probabilidade de a respos- ta emitida poder ser tanto reforçada positivamente quanto punida.

Para o estudo da ansiedade, modelos experimentais vêm sendo desenvolvidos. Esses modelos visam a testar novos ansiolíticos, descobrir bases neurobiológicas da ansiedade, bem como esclarecer os limites do conceito (Silva, 1997). Um modelo é um arranjo composto por um aparato e um

\footnotetext{
${ }^{1}$ Endereço para correspondência: Rua Augusto Corrêa, 01, Guamá - Belém/PA - CEP: 66075-110. Tel.: (91) 8174-7142 / (91) 9632-1808. E-mail:pauladaniellecarvalho@gmail.com/gouveiajr.a@gmail.com
} 
procedimento que caracteriza uma manipulação referente a uma categoria comportamental (Gouveia Jr., Maximino, \& Brito, 2007). Todos os modelos de ansiedade envolvem algum tipo de estimulação aversiva, como, por exemplo, a exposição do animal a ambientes novos ou potencialmente perigosos, predadores ou a estímulos com esses relacionados ou pelo ataque ou confronto entre coespecíficos. Os modelos de ansiedade podem envolver tanto respostas instrumentais quanto respostas emitidas sem a necessidade de modelagem; estas últimas, ao dispensarem modelagem, facilitam o desenvolvimento de testes simples e rápidos para a seleção de drogas ansiolíticas, como, por exemplo, os benzodiazepínicos (Cruz, Zangrossi Jr., Graeff, \& Landeira-Fernandez, 1997).

Os benzodiazepínicos agem potencializando a ação inibitória do ácido gama-aminobutírico (GABA) no sistema nervoso central, e um dos efeitos dessa ação é a redução da ansiedade. Entre os benzodiazepínicos, destacam-se diazepam, bromazepam, lorazepam, flunitrazepam e oxazepam (Rang, Dale, Ritter, \& Flower, 2007).

Em estudos com peixes, um modelo de ansiedade que vem sendo utilizado é o modelo de esquiva inibitória (Faganello \& Mattioli, 2008; Garção \& Mattioli, 2009). Esse modelo é baseado na preferência por ambientes escuros e aversão a ambientes claros que diversas espécies de peixes teleósteos apresentam (Gouveia Jr. et al., 2007). Gouveia Jr., Mattioli, Morato, Ramos, Silva e Zampieri (2005) verificaram que o peixe-dourado, espécie aqui utilizada, também possui preferência por ambientes escuros. A preferência por escuridão é considerada um comporta- mento antipredatório, uma vez que espécies que exibem tal comportamento geralmente vivem em águas rasas e são predadas majoritariamente por pássaros quando sobem à superficie.

Dessa forma, ficar no fundo ou em um ambiente escuro seria uma medida de proteção contra possíveis predadores (Gouveia Jr. et al., 2005); porém, assim como o animal possui tendência natural a se esquivar de ambientes claros, ele também possui a mesma tendência para explorar novos ambientes. Essa situação gera um contexto no qual o animal é exposto a um conflito entre explorar ou não tais ambientes e exibe comportamentos de aproximação e evitação destes, o que caracteriza uma possível forma de ansiedade (Maximino et al., 2007; Gouveia Jr. et al., 2005; Montgomery, 1955).

A esquiva inibitória é um procedimento caracterizado pela não emissão, pela diminuição da emissão ou, ainda, pelo aumento na latência de emissão de determinada resposta, dada a probabilidade de esta vir a ser punida. Drogas benzodiazepínicas costumam prejudicar a esquiva inibitória, com o animal demorando menos tempo para passar para o ambiente claro. Tal efeito é considerado como um índice de diminuição de comportamentos tipo-ansiedade, na medida em que o animal enfrenta mais o estímulo aversivo (Silva, 1997).

Este trabalho visa a estudar os efeitos de uma droga benzodiazepínica, o clonazepam, com o objetivo de verificar seus efeitos sobre a esquiva inibitória do peixe-dourado (Carassius auratus), que possui aversão natural a ambientes claros, não havendo relatos de seu uso nesse modelo e com essa espécie. 


\section{MÉTODO}

\section{Sujeitos}

Foram utilizados 30 peixes da espécie Carassius auratus, de sexo e idade indefinidos, pesando em média 3,95 g, adquiridos em uma loja de aquarismo local (Vitória Régia, Belém/PA, Brasil), mantidos em grupo de 15 animais por aquário. Os sujeitos foram alojados para habituação antes do experimento em aquários de 25 litros; a temperatura da água foi mantida em torno de $27^{\circ} \mathrm{C}$; os animais foram alimentados uma vez ao dia com ração em flocos Tetracolor (Tetra GmbH, Alemanha).

\section{Materiais}

Aquário de vidro retangular, com $45 \mathrm{~cm}$ de comprimento, $10 \mathrm{~cm}$ de largura e $15 \mathrm{~cm}$ de altura, dividido por uma porta guilhotina em dois ambientes, sendo um branco - 30 $\mathrm{cm}$ de comprimento, $10 \mathrm{~cm}$ de largura e 10 $\mathrm{cm}$ de altura - e um preto $-10 \mathrm{~cm}$ de comprimento, $15 \mathrm{~cm}$ de altura e $10 \mathrm{~cm}$ de largura. Esse aquário é uma variação de aquários utilizados em estudos de esquiva inibitória em outros trabalhos (Mattioli, Nelson, Huston, \& Spieler, 1998) que foi modificado com o objetivo de aumentar a possibilidade de o animal expor-se ao estímulo aversivo e diminuir a exploração não voltada para a tarefa-fim pelo aumento da área clara do aparato.

\section{Tratamento farmacológico}

Foi utilizado o clonazepam (Roche, Brasil) $0,5 \mathrm{mg} / \mathrm{ml}$. Foram colocados $86 \mathrm{ml}$ de água em um recipiente plástico com volume de $250 \mathrm{ml}$, no qual se colocou o animal, e então foram injetadas na água diferentes quantidades do fármaco que, consequente- mente, resultaram em diferentes concentrações. Dessa forma, foram administradas concentrações de $0,001 \mathrm{mg} / \mathrm{ml}, 0,003 \mathrm{mg} / \mathrm{ml} \mathrm{e}$ $0,006 \mathrm{mg} / \mathrm{ml}$; para cada animal foi preparado um banho. Cada animal passou três minutos exposto ao fármaco e, em seguida, foi retirado e colocado na caixa branca e preta para o procedimento comportamental.

\section{Procedimento comportamental}

Os experimentos foram conduzidos no período da manhã, com início às $9 \mathrm{~h}$. Os animais foram alimentados 30 minutos antes do experimento, pesados e medidos em seu comprimento. Os sujeitos foram divididos em quatro grupos: Controle $(\mathrm{n}=9)$, Grupo $1(\mathrm{n}=7)$, Grupo $2(\mathrm{n}=7)$ e Grupo 3 $(\mathrm{n}=7)$, conforme a concentração de fármaco (respectivamente, 0, 0,001, 0,003 e 0,006 $\mathrm{mg} / \mathrm{ml})$. A altura da coluna d'água foi de 7 $\mathrm{cm}$. Cada animal foi colocado inicialmente no compartimento preto e ali mantido por três minutos para habituação. Decorrido esse tempo, a porta foi erguida suavemente, passando o animal a ter acesso a todo o aparato. Foi registrado o tempo - latência - que o animal levava para atravessar para o compartimento branco. $\mathrm{O}$ critério de travessia era de dois terços do comprimento do animal no compartimento branco. Cada travessia correspondia a uma tentativa, sendo sete tentativas no total. Tentativas com latências igual a 180 segundos foram consideradas como falhas. Após cada tentativa, a porta foi recolocada e o animal foi delicadamente levado de volta ao compartimento preto, em uma rede própria para peixes, para uma nova tentativa. O número de tentativas seguiu estudos prévios feitos em nosso laboratório e ainda não publicados. Os valores das concentrações, via 
de administração e tempo de absorção da droga foram definidos arbitrariamente, visto que não há relatos de estudos que utilizaram um procedimento experimental semelhante.

\section{Análise estatística}

As latências de entrada no compartimento branco foram registradas manualmente e, posteriormente, representadas em termos de média \pm erro padrão das latências absolutas. A análise estatística foi realizada em dois momentos: inicialmente, foi feita uma ANOVA de um fator (grupo) de medidas repetidas (tentativas) para a análise do efeito das concentrações no processo de aprendizagem dos grupos. Em um segundo momento, a análise das latências foi realizada através de ANOVA de dois fatores, um fator intrassujeito (tentativas) e um fator entressujeitos (grupos), com vistas a determinar o efeito da droga sobre as latências médias dos grupos. Em seguida, foi utilizado o post hoc de Dunnet.

Para a análise das falhas, foi realizado o teste de Kruskal-Wallis.

\section{Resultados}

A Figura 1 mostra as latências médias \pm erro padrão de cada grupo ao longo das tentativas. Na figura, quando se compara a primeira tentativa com as últimas, percebe-se que houve um aumento nos valores das latências em todos os grupos, sendo o grupo com concentração de $0,006 \mathrm{mg} / \mathrm{ml}$ o que apresentou os menores valores nas primeiras latências.

A ANOVA de dois fatores (tentativa e grupo) mostrou diferença estatisticamente significativa na latência entre as tentativas $\left[\mathrm{F}_{(6,182)}=4,687, \mathrm{p}=0,001\right]$ e entre os grupos $\left[\mathrm{F}_{(3,182)}=3,915, \mathrm{p}=0,010\right]$, não havendo interação entre os dois fatores $\left[\mathrm{F}_{(18,182)}=0,572, \mathrm{p}=0,916\right] . \mathrm{O}$ teste de Dunnet mostrou que houve diferença entre as tentativas $1 \times 6$ e $1 \times 7$ e entre o grupo controle e o grupo de concentração 0,006 $\mathrm{mg} / \mathrm{ml}$.

A Figura 2 mostra as médias das tentativas falhas (latência $=180 \mathrm{~s}$ ) de cada grupo;

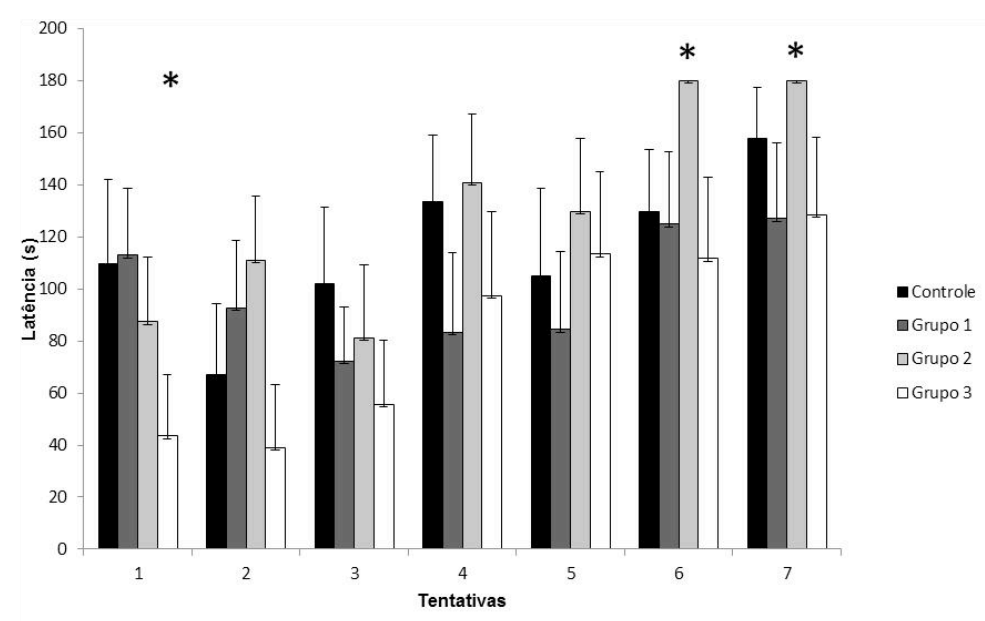

Figura 1. Latências (média \pm erro padrão) do grupo controle e dos grupos tratados com clonazepam no teste de esquiva inibitória ao longo das tentativas. Houve diferenças significativas entre o grupo controle e o grupo com a concentração de $0,006 \mathrm{mg} / \mathrm{ml}$ e entre as tentativas 1 e 6 e 1 e $7 . \mathrm{O}$ asterisco indica as tentativas que apresentaram diferenças entre si. 
o grupo $0,006 \mathrm{mg} / \mathrm{ml}$ apresentou a menor média de tentativas falhas, e o grupo de concentração $0,003 \mathrm{mg} / \mathrm{ml}$, a maior. A análise realizada (teste de Kruskal-Wallis) não mostrou diferenças significativas entre os grupos quanto às tentativas falhas $\left[\mathrm{H}_{(3)}=4,441 \mathrm{p}=\right.$ 0, 220]. to branco foi preservado, evidenciado pelos maiores valores da latência nas últimas tentativas, ou seja, o animal demorou mais tempo, ao longo das tentativas, para sair do compartimento preto. Esse fato pode ser explicado pelo efeito da aprendizagem, pois, embora a tendência a se esquivar de ambientes claros

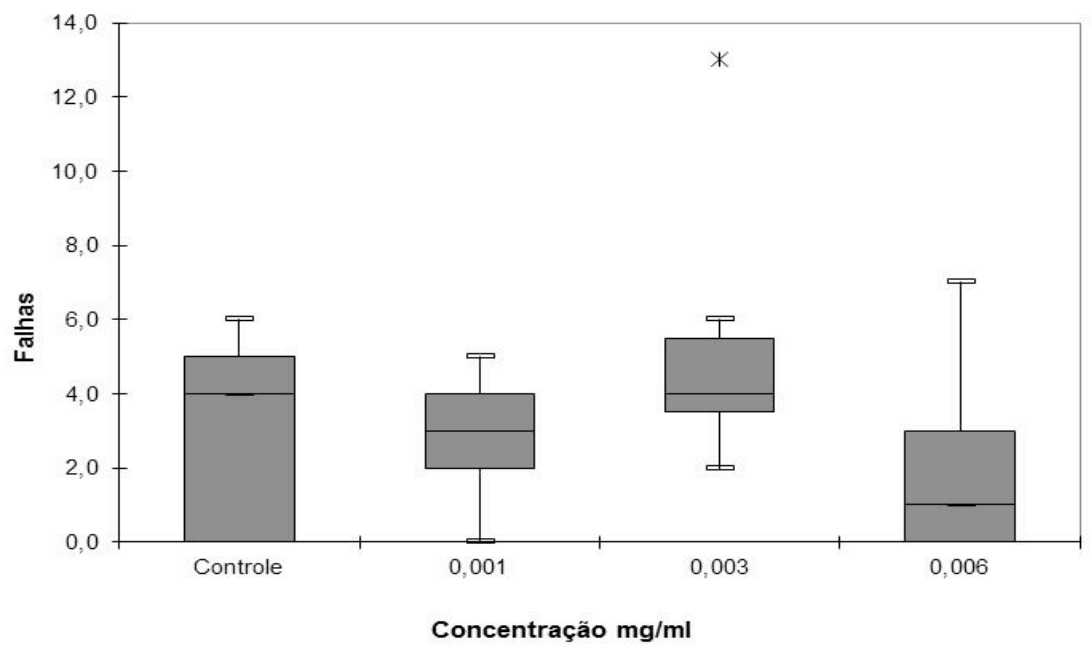

Figura 2. Médias e erro padrão das tentativas falhas de cada grupo. Não houve diferenças significativas entre os grupos.

\section{DisCUSSÃo}

No presente trabalho, foi utilizada uma droga ansiolítica, o clonazepam, a fim de verificar seus efeitos na esquiva inibitória. A análise estatística mostrou que houve diferenças significativas entre as tentativas e entre os grupos; o pós-teste mostrou que a diferença ocorreu entre as tentativas 1 e 6 e entre as tentativas 1 e 7 , e entre o grupo controle e o Grupo 3 (0,006 mg/ml).

Os dados sugerem que não houve prejuízo da esquiva inibitória com as menores concentrações; a diferença entre as tentativas indica que, embora sob efeito de uma droga ansiolítica, o valor aversivo do compartimen- possa possuir um componente inato, a aprendizagem de esquiva de um ambiente específico só ocorre quando da exposição do sujeito a este, tendo como consequência o aumento da latência de travessia para esse ambiente (Medalha, Coelho, \& Mattioli, 2000).

A diferença entre o grupo controle e o grupo exposto à concentração $0,006 \mathrm{mg} / \mathrm{ml}$ sugere o efeito ansiolítico deste último em relação ao controle, o que pode ser observado pelas menores latências de travessia para o compartimento branco no grupo exposto à maior concentração de clonazepam, fato que sugere que, com essa droga, nesse modelo, o efeito ansiolítico é alcançado com a maior concentração. Faganello e Mattioli 
(2007) realizaram um estudo com o modelo de esquiva inibitória, com peixes-dourados, no qual uma das drogas utilizadas foi o diazepam, também um benzodiazepínico. Em tal estudo, foi feito o teste do efeito da droga sobre componentes locomotores do animal e foi obtido que o diazepam não alterou a atividade locomotora do animal em tal modelo. Portanto, tal como o diazepam, o clonazepam não deve interferir na atividade locomotora do animal a ponto de considerarmos as menores latências de entrada no compartimento branco como, simplesmente, uma melhora na locomoção.

Esses dados assemelham-se a estudos que investigaram os efeitos de benzodiazepínicos na esquiva inibitória em camundongos, em que foi relatado que a administração de benzodiazepínicos prejudicou a tarefa de esquiva inibitória com o animal, exibindo significativamente menos tempo para entrar no compartimento no qual sua resposta foi punida (Nabeshima, Tohyama, Ichihara, \& Kameyama, 1990; Voigt \& Morgenstern, 1992).

Os animais que receberam a concentração de $0,003 \mathrm{mg} / \mathrm{ml}$ apresentaram maiores latências nas tentativas 6 e 7 e maior número de tentativas falhas. Diante de tais resultados, acreditamos que tenha acontecido um fenômeno denominado hormese, de acordo com o qual uma droga, em determinada concentração, não só não produz o efeito esperado como produz um efeito paradoxal (Calabrese, 2004). Assim, com tal concentração, pode ter ocorrido tal efeito paradoxal com facilitação da aprendizagem, e não de prejuízo.

Em relação às tentativas falhas, a menor média foi exibida pelo grupo que recebeu a maior concentração $(0,006 \mathrm{mg} / \mathrm{ml})$, e a maior média, pelo grupo que recebeu con- centração intermediária $(0,003 \mathrm{mg} / \mathrm{ml})$; porém, não houve diferenças significativas entre os grupos quanto às falhas, o que mostra que o clonazepam não alterou o número de falhas entre os grupos. Portanto, embora não se tenham obtido diferenças significativas entre os grupos em relação às tentativas falhas, esses dados das falhas corroboram o que foi mencionado, que o efeito ansiolítico, com essa droga, nesse modelo e com a espécie utilizada, é alcançado somente com a maior concentração administrada.

Assim, podemos concluir, a partir de nossos dados, que o clonazepam mostrou efeito ansiolítico, em relação ao controle, com a maior concentração aqui administrada, evidenciado pelas menores latências no grupo que a recebeu. Porém, o aumento nos valores das latências ao longo das tentativas mesmo no grupo em que foi observado o efeito ansiolítico sugere que, embora o animal que recebeu maior concentração de clonazepam tenha se exposto mais ao ambiente claro, tal fato não suprimiu completamente sua aversão natural por esse ambiente.

\section{REFERÊNCIAS}

Blanchard, D. C., \& Blanchard, J. R. (1988). Ethoexperimental approaches to the biology of emotion. Annual Review of Psychology, 39, 43-68.

Calabrese, E. J. (2004). Hormesis: from marginalization to mainstream: A case for hormesis as the default dose-response model in risk assessment. Toxicology and Applied Pharmachology, 197, 125-136.

Cruz, A. P. M., Zangrossi Jr., H., Graeff, F. G., \& Landeira-Fernandez, J. (1997). Modelos animais de ansiedade: implicações para a seleção de drogas ansiolíticas. Psicologia: Teoria e Pesquisa, 13, 269-278. 
Faganello, F. R., \& Mattioli, R. (2007). Anxiolytic-like effect of chlorpheniramine in inhibitory avoidance in goldfish submitted to telencephalic ablation. Progress in Neuro-Psychopharmacology E Biological Psychiatry, 31, 269-274.

Faganello, F. R., \& Mattioli, R. (2008). Chlorpheniramine facilitates inhibitory avoidance in teleosts submitted to telencephalic ablation. Brazilian Journal of Medical and Biological Research, 41,398-402.

Garção, D. C., \& Mattioli, R. (2009). L-histidine reduces inhibitory avoidance in Carassius auratus submitted to cerebellar ablation. Brazilian Journal of Medical and Biological Research, 42, 135-140.

Gouveia Jr., A., Mattioli, R., Morato, S., Ramos, L. A., Silva, E. F., \& Zampieri (2005). Preference of goldfish (Carassius auratus) for dark places. Revista de Etologia, 7, 63-66.

Gouveia Jr., A., Maximino, C., \& Brito, T. M. (2007). Comportamento de peixes: vantagens e utilidades nas neurociências. Faculdade de Ciências, Unesp, Bauru, SP.

Graeff, F. G. (2007). Ansiedade experimental humana. Revista de Psiquiatria Clínica, 34, 251-253.

Mattioli, R., Nelson, C. A., Huston, J. P. \& Spieler, R. E.(1998). Conditioned place-preference analysis in the goldfish with the H1 histamine antagonist chlorpheniramine. Brain Research Bulletin, 45, 41-44.

Maximino, C., Brito, T. M., Moraes, F. D., Oliveira, F. V. C., Taccolini, I. B., Pereira, P. M., Colmanetti, R., Lozano, R., Gazolla, R. A., Tenório, R., Lacerda, R. I. T., Rodrigues, S. T. K., Lameirão,
S.V. O. C., Pontes, A. A. A., Romão, C. F., Prado, V. M., \& Gouveia Jr, A. (2007). A comparative analysis of the preference for dark environment in five teleosts. International Journal of Comparative Psychology, 20, 351-367.

Medalha, C. C., Coelho, J. L., \& Mattioli, R. (2000). Analysis of the role of histamine in inhibitory avoidance in goldfish. Progress in Neuro-Psychopharmachology \& Biological Psychiatry, 24, 295-305. Montgomery, K. C. (1955). The relation between fear induced by novel stimulation and exploratory behavior. Journal of Comparative Physiological Psychology, 48, 254-260.

Nabeshima, T., Tohyama, K., Ichihara, K., \& Kameyama, T. (1990). Effects of benzodiazepines on passive avoidance response and latent learning in mice: Relationship to benzodiazepine receptors and the cholinergic neural system. The Journal of Pharmachology and Experimental Therapeutics, 255, 789-794.

Rang, H. P., Dale, M. M., Ritter, J. M., \& Flower, R. J. (2007). Farmacologia (6a ed.). Rio de Janeiro: Elsevier.

Silva, M.T.A. (1997). Modelos animais de ansiedade. In D. R. Zamignani (Org.). Sobre comportamento e cognição: a aplicação da análise do comportamento e da terapia cognitivo-comportamental no hospital geral e nos transtornos psiquiátricos (Vol. 3). São Paulo: Arbytes.

Voigt, J. P., \& Morgenstern, E. (1992). Comparative effects of carbamazepine, phenytoin, diazepam and clonazepam on inhibitory avoidance learning in mice. Psychopharmachology, 108, 131-135. 


\section{A Psicologia Como Estudo de Interações João Claudio Todorov}

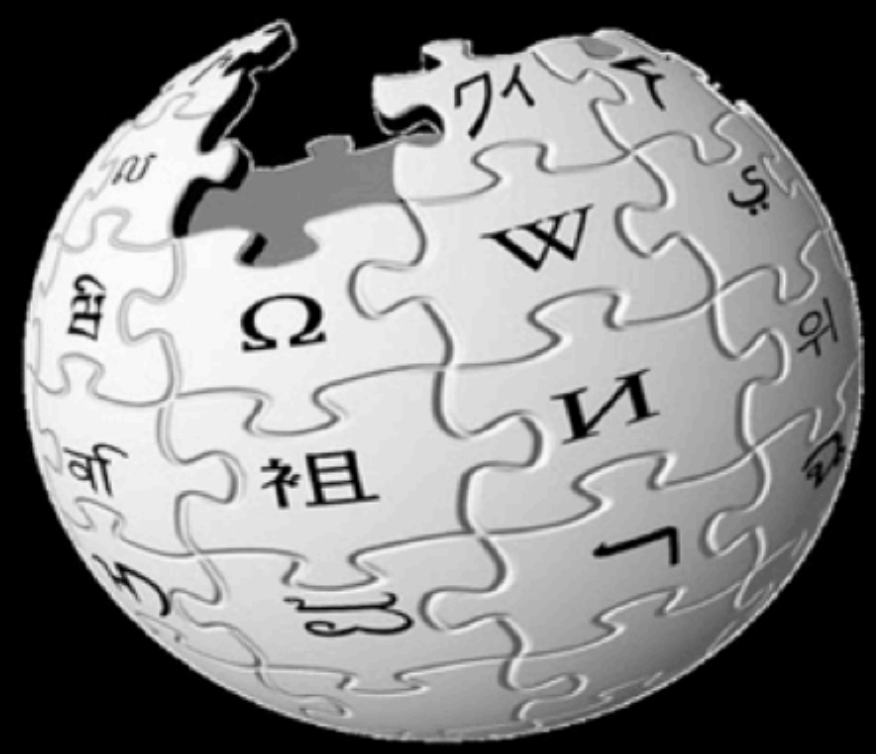

http://www.walden4.com.br/pww4/index.php?title=A_Psicologia_como_Estudo_de_Interações A Psicologia com Estudo de Interações Organizado por João Claudio Todorov Brasília: Instituto Walden4, 2012

$120 \mathrm{p}$.

ISBN: 978-85-65721-00-4

1. Psicologia 2. Behaviorismo 3. Análise do comportamento

I. Todorov, J. C., org. 